\title{
EFEITO DO TIPO DE COMPACTAÇÃO, POR IMPACTO OU POR AMASSAMENTO, NO TEOR DE LIGANTE E COMPORTAMENTO MECÂNICO DE MISTURAS ASFÁLTICAS
}

\author{
F. Gadler ${ }^{1}$; J. Villena ${ }^{2}$; L. F. R. Miranda ${ }^{3}$ \\ 1,2,3 Programa de Pós-Graduação em Engenharia de Construção Civil, Universidade Federal do Paraná, Centro \\ Politéenico, Bloco III, Jd. das Américas, Curitiba/PR, CEP 81531-980 \\ fernandagadler@gmail.com ${ }^{1}$,joevillena@gmail.com², reciclagem.miranda@gmail.com ${ }^{3}$
}

\begin{abstract}
Resumo: Durante a evolução dos procedimentos de dosagem de misturas asfálticas, diversas formas de compactação de amostras vêm sendo desenvolvidas, podendo ser realizada através de impacto, amassamento, vibração ou rolagem. O método de dosagem mais difundido mundialmente é denominado método Marshall, que faz uso da compactação por impacto. A partir dos anos 90 foi desenvolvido o método Superpave, sendo a forma de compactação por amassamento a principal contribuição desta nova sistemática. A presente pesquisa avalia a influência do método de compactação nos parâmetros de dosagem e no comportamento mecânico de misturas asfálticas (RT e MR). Foi realizada a dosagem de duas misturas asfálticas com os mesmos materiais e granulometria e, em seguida foram moldados corpos de prova cilíndricos utilizando dois tipos de compactaçáo; impacto e amassamento. Os resultados apontam para a reduçáo de $0,5 \%$ do teor ótimo de ligante das misturas asfálticas compactadas por amassamento, no compactador giratório Superpave, em comparação com as misturas compactadas por impacto no compactador Marshall. As duas misturas apresentaram valores semelhantes quanto aos parâmetros de RT e MR, sendo que a mistura compactada através do compactador Superpave apresentou menor RT e maior MR do que a mistura compactada no compactador Marshall, possivelmente pelo menor teor de ligante, efeito este positivo do ponto de vista de deformabilidade da mistura.
\end{abstract}

Palavras-chave: Dosagem, Compactação, Marshall, Superpave, Comportamento mecânico.

\begin{abstract}
The present research evaluates the influence of the compaction method on the dosage parameters and the mechanical behavior of asphalt mixtures (tensile strength ratio and resilient modulus). Two asphalt mixtures were produced with the same materials and gradation, and then cylindrical specimens were molded using two types of compaction; impact and kneading. The results point to the reduction of $0.5 \%$ of the optimum binder content of the compacted asphalt mixtures by kneading in the Superpave gyratory shear compactor in comparison to the impact compacted mixtures in the Marshall compactor. The two mixtures presented similar values for the tensile strength ratio and resilient modulus, and the compacted mixture in Superpave gyratory shear compactor presented lower tensile strength ratio and higher resilient modulus than the one that is compacted in Marshall compactor, a fact that is positive to deformability of the mixture.
\end{abstract}

Keywords: Design, Compaction, Marshall, Superpave, Mechanical behavior. 


\section{Introduçáo}

A dosagem de uma mistura asfáltica tem consistido até hoje na escolha, através de procedimentos experimentais, de um teor dito "ótimo" de ligante, a partir de uma faixa granulométrica predefinida. Durante a evoluçáo dos procedimentos de dosagem, diversas formas de compactação de amostras vêm sendo desenvolvidas, podendo ser realizada através de impacto, amassamento, vibração ou rolagem. $\mathrm{O}$ método de dosagem mais difundido em escalada mundial é denominado método Marshall, que faz uso da compactação por impacto e foi desenvolvido pelo engenheiro Bruce Marshall na década de 1940 [1].

Ocorre que, na década de 80 muitas rodovias americanas de alto volume de tráfego apresentaram problemas prematuros relacionados à deformaçáo permanente, moralmente atribuídas a um excesso de ligante nas misturas asfálticas. O corpo técnico acreditava que a compactação por impacto, durante o procedimento de dosagem Marshall, produzia corpos de prova com densidades distintas daquelas apresentadas pelas misturas em campo. Somado a isso, o aumento do número de solicitaçóes e da magnitude do carregamento dos veículos acarretou em um grande estudo do Strategic Highway Research Program (SHRP) entre 1987 e 1992. Um dos importantes resultados desse programa de pesquisa foi o desenvolvimento do método de dosagem de misturas denominado Superpave, sendo a forma de compactação, por amassamento, a principal contribuição desta nova sistemática. $\mathrm{O}$ método foi concebido na intenção de reproduzir o nível de compactação de campo e, para tal, faz uso do compactador giratório Superpave que aplica um esforço de pressão sobre a mistura através de giros, produzindo efeito similar ao que acontece quando da ação dos rolos compactadores em campo [2]. Ainda, existe a metodologia francesa de dosagem de misturas asfálticas que, dentre outras características distintas, faz uso da compactação por rolagem, diferente da compactação por impacto da dosagem Marshall e da compactação por amassamento da dosagem Superpave.

A compactação das misturas asfálticas tem papel importante no desempenho da camada onde esse material será aplicado, portanto, corpos de prova compactados de maneira diferente podem levar a teores ótimos de ligante diferentes e, em consequência, resultar em misturas com comportamento mecânico distinto.

Apesar da ampla disseminação do uso do método Marshall no Brasil, que representa um aspecto positivo de experiência adquirida ao longo do tempo, a realidade ainda reflete em projetos de dosagem que apresentam desempenho diferente quando em operação. Em contrapartida, o método Superpave ainda é limitado a poucos centros de pesquisa e algumas universidades no país, com certa resistência dos adeptos a metodologia Marshall [3].

Diante do exposto, a presente pesquisa visa avaliar a influência do método de compactação, por impacto ou por amassamento, na definição do teor ótimo de ligante e no comportamento mecânico, resistência à tração e módulo de resiliência, das misturas asfálticas. 


\section{Metodologia}

Todos os ensaios, tanto de caracterização dos materiais, dosagem e caracterização mecânica, foram realizados no Laboratório de Pavimentação Professor Armando Martins (LAMP) da Universidade Federal do Paraná (UFPR). A seguir estão detalhados os materiais utilizados, a metodologia de dosagem e os ensaios realizados.

\subsection{Materiais utilizados}

As misturas foram confeccionadas com agregados naturais de origem granítica, provenientes da pedreira Nova Prata Mineração, localizada no município de Paranaguá/PR, coletados nas fraçóes granulométricas correspondentes, quais sejam, brita, pedrisco e pó de pedra. Ainda, para produção das misturas, foi utilizado ligante asfáltico convencional, classificado como 50/70, proveniente da Usina Nova Prata, localizada no município de Paranaguá/PR, cuja origem é da REPAR - Refinaria Presidente Getúlio Vargas da Petrobrás, localizada em Araucária-PR.

Os agregados foram caracterizados quanto aos ensaios de granulometria (NBR NM 248/2003), absorção de água (NBR NM 30/2001), massa específica real e aparente (ABNT NBR NM 53/2009) e teor de finos (ABNT NBR NM 46/2003). Para a seleção granulométrica foi utilizado o método Bailey e, de acordo com as diretrizes do método, além da utilização das peneiras específicas para a determinação da granulometria, foram calculadas as massas específicas solta e compactada, conforme a norma AASHTO T19. Os resultados da caracterização dos agregados estáo apresentados na Tabela 1.

Tabela 1 - Caracterização dos agregados.

\begin{tabular}{cccc}
\hline Parâmetro & \multicolumn{3}{c}{ Agregados } \\
& Brita & Pedrisco & Pó de pedra \\
\hline Massa específica aparente $\left(\mathrm{g} / \mathrm{cm}^{3}\right)$ & 2,40 & 2,59 & 2,51 \\
Massa específica real $\left(\mathrm{g} / \mathrm{cm}^{3}\right)$ & 2,57 & 2,66 & 2,55 \\
Absorção de água $(\%)$ & 2,74 & 1,03 & 1,14 \\
Teor de finos $(\%)$ & 0,18 & 0,45 & 10,01 \\
Massa específica solta $\left(\mathrm{kg} / \mathrm{m}^{3}\right)$ & 1.321 & 1.296 & 1.807 \\
Massa específica compactada $\left(\mathrm{kg} / \mathrm{m}^{3}\right)$ & 1.487 & 1.454 & 2.070 \\
\hline
\end{tabular}

\subsection{Dosagem}

Como o processo de compactação é a variável principal do estudo, a granulometria da mistura asfáltica foi a mesma para as duas amostras confeccionadas. Para tal, foi utilizado o método Bailey de seleção granulométrica, por se tratar de um método mais analítico e menos empírico, que leva em conta o intertravamento dos agregados baseado no conceito de empacotamento de partículas. Esse método fornece a assistência necessária para garantir que as misturas serão projetadas de modo a 
proporcionar boa resistência à deformação permanente, longa durabilidade ou desempenho de longo prazo com os agregados disponíveis [7]. Além disso, o método é de fácil aplicação em laboratório e reprodução em campo, obtendo boa densidade de maneira prática. A metodologia foi desenvolvida pelo engenheiro Robert Bailey, do Departamento de Transportes de Illinois (IDOT), sendo refinado nas pesquisas de Vavrik et al. a partir dos anos 2000, fazendo com que ele se torne aplicável a qualquer mistura asfáltica, independentemente do tamanho do agregado, e a qualquer método de dosagem [8]. Os percentuais de incorporação das fraçôes de agregados foram sendo ajustados de modo que se enquadrassem em um valor médio entre os limites de proporção de agregado graúdo (proporção AG) propostos pelo método. A Figura 1 apresenta a curva granulométrica das duas misturas. Somente a título de apresentação, foram plotados no gráfico os limites inferior e superior da Faixa "C", utilizada em camadas de rolamento de granulometria densa, proposta pelo órgão regulador no Brasil, o Departamento Nacional de Infraestrutura de Transportes (DNIT).

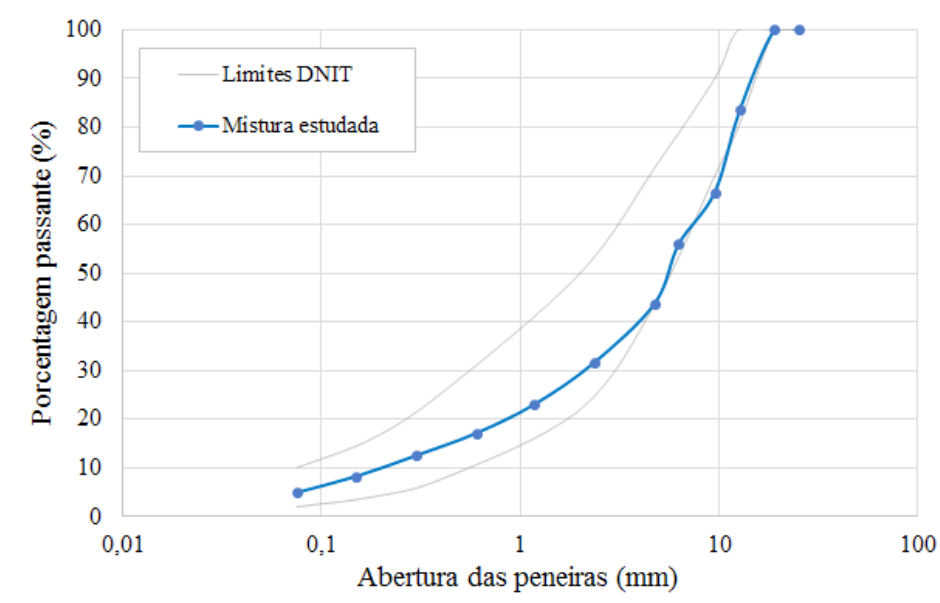

Figura 1 - Curva granulométrica da mistura estudada.

A partir da seleção granulométrica, foram dosados, conforme diretrizes da metodologia Marshall, cinco teores de ligante para cada uma das misturas que seriam compactadas de formas diferentes, sendo a primeira por impacto com o soquete Marshall e a segunda por amassamento no compactador giratório Superpave. Os teores de ligante utilizados variaram de 4,0\%, 4,5\%, 5,0\%, 5,5\% até $6,0 \%$, sendo 3 corpos de prova de cada um dos teores de ligante, para cada uma das misturas estudadas, denominadas de Marshall e Superpave. Após a usinagem, as misturas foram acondicionadas em estufa, na temperatura de compactação por duas horas, a fim de simular o efeito do envelhecimento da mistura a curto prazo. Além disso, também foram dosadas amostras para determinação da massa específica máxima medida pelo método RICE, obedecendo a norma AASHTO T209-05, normatizado no Brasil pela NBR 15619/2016.

As temperaturas de usinagem e de compactação foram obtidas graficamente a partir da curva viscosidade-temperatura do ligante asfáltico, obtidas nas três temperaturas do ensaio de viscosidade 
Brookfield (ASTM D2493, 2009), com base nas medidas de viscosidade obtidas nas três temperaturas de ensaio $\left(135,150\right.$ e $\left.177^{\circ} \mathrm{C}\right)$. Neste caso, a temperatura de usinagem e compactação foram definidas em $150^{\circ} \mathrm{C}$ e $140^{\circ} \mathrm{C}$, respectivamente. Além disso, foram calculados os parâmetros volumétricos previstos na dosagem Marshall para as duas misturas compactadas de maneira distinta (Marshall e Superpave). O teor ótimo de ligante foi definido em função da avaliação destes parâmetros, a partir da análise da variação do volume de vazios $\left(\mathrm{Vv}_{\mathrm{v}}\right)$ e da relação betume vazios (RBV).

\subsection{Compactaçáo}

O primeiro conjunto de amostras foi compactado, após usinagem, utilizando soquete mecânico Marshall (Figura 3(a)), com a aplicação de 75 golpes em cada face do corpo de prova. Para a compactação pelo método Superpave, é necessária a definição da quantidade de giros a serem realizados pelo compactador giratório (Figura 3(b)). Esse parâmetro é funçáo do tráfego a que o pavimento estará sendo solicitado, conforme Tabela 2. Por conta disso, as misturas foram compactadas com 100 giros, que corresponde ao número de giros utilizados para misturas asfálticas dosadas pela metodologia Superpave para um tráfego de médio a alto, equivalendo aos 75 golpes do compactador Marshall.

Tabela 2 - Número de giros em função do tráfego.

\begin{tabular}{cccc}
\hline $\begin{array}{c}\text { Tráfego de projeto, } \\
\text { ESAL (x10 } \mathbf{~}^{6}\end{array}$ & Inicial $\mathbf{N}_{\text {ini }}$ & $\begin{array}{c}\text { Número de Giros } \\
\text { Projeto } \mathbf{~}_{\text {des }}\end{array}$ & Máximo $\mathbf{N}_{\text {máx }}$ \\
\hline$<0,3$ & 6 & 50 & 75 \\
0,3 a 3 & 7 & 75 & 115 \\
3 a 30 & 8 & 100 & 160 \\
$\geq 30$ & 9 & 125 & 205 \\
\hline \multicolumn{4}{c}{}
\end{tabular}
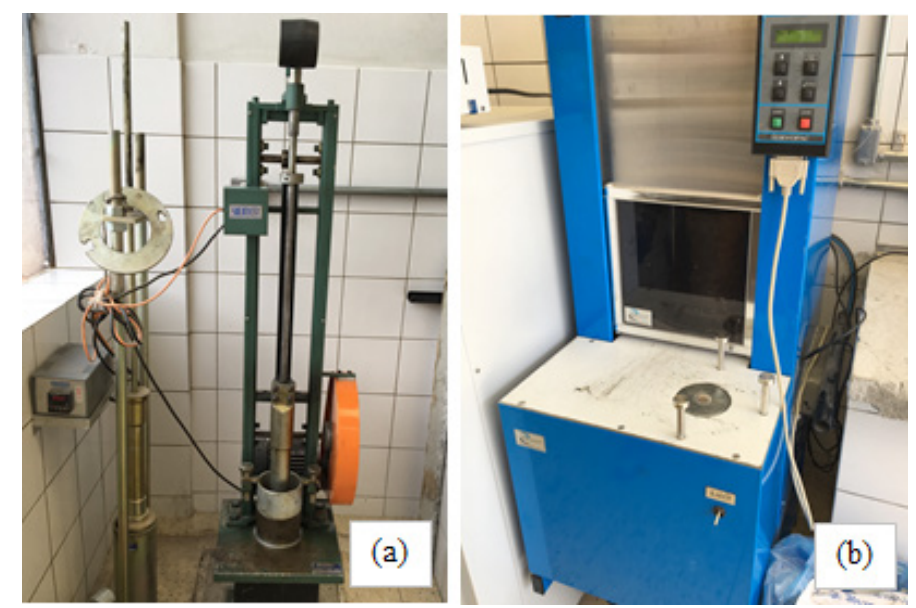

Figura 3 - (a) soquete Marshall; (b) compactador giratório Superpave. 


\subsection{Caracterizaçáo mecânica}

A partir da definição do teor ótimo de ligante para ambas misturas, foram moldados cinco corpos de prova para cada tipo de compactação (Marshall e Superpave), e os mesmos foram avaliados quanto às suas características mecânicas, através dos ensaios de resistência a tração estática por compressão diametral (RT) e módulo de resiliência (MR), conforme Figura 4. O ensaio de MR foi executado de acordo com a norma ASTM D412 e o ensaio de RT seguiu a norma DNIT 136/2010-ME.

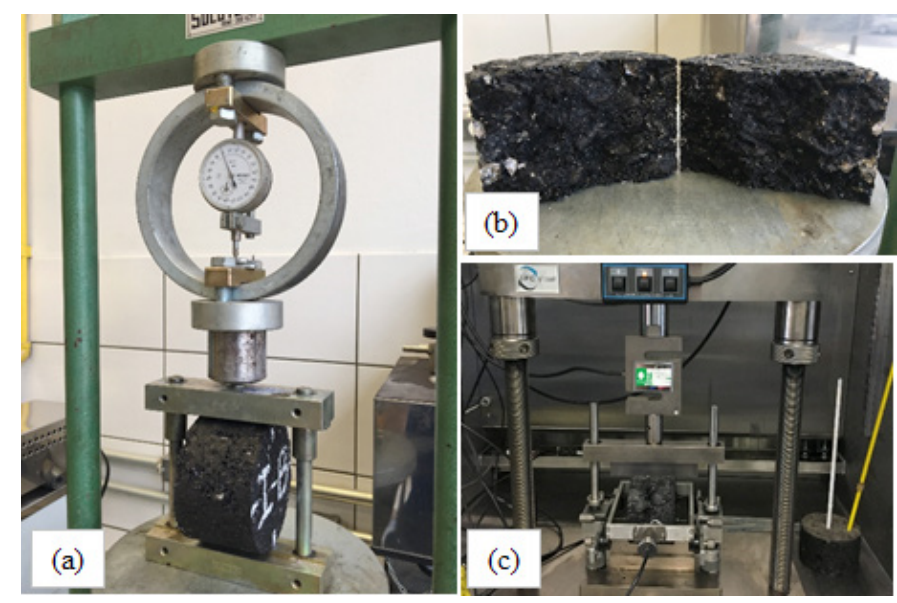

Figura 4 - (a) Ensaio de RT em andamento; (b) corpo de prova rompido; (c) ensaio de MR em andamento.

\section{Resultados}

A partir dos parâmetros volumétricos e mecânicos determinados na dosagem Marshall das misturas compactadas pelo método Marshall e Superpave (Tabela 3), foram plotadas seis curvas em função do teor de asfalto, para determinação do teor ótimo, conforme apresentado na Figura 5.

Tabela 3 - Parâmetros volumétricos das misturas estudadas.

\begin{tabular}{|c|c|c|c|c|c|c|c|c|c|c|}
\hline \multirow{2}{*}{ Parâmetros } & \multicolumn{5}{|c|}{ Marshall } & \multicolumn{5}{|c|}{ Superpave } \\
\hline & 4,0 & 4,5 & 5,0 & 5,5 & 6,0 & 4,0 & 4,5 & 5,0 & 5,5 & 6,0 \\
\hline $\begin{array}{l}\text { Massa esp. máx. medida (g/ } \\
\left.\mathrm{cm}^{3}\right)\end{array}$ & 2,511 & 2,500 & 2,479 & 2,473 & 2,443 & 2,511 & 2,500 & 2,479 & 2,473 & 2,443 \\
\hline Volume de vazios, Vv (\%) & 6,5 & 5,6 & 4,4 & 3,9 & 3,1 & 6,0 & 4,9 & 2,9 & 2,4 & 1,5 \\
\hline $\begin{array}{l}\text { Massa esp. aparente, Gmb } \\
\left(\mathrm{g} / \mathrm{cm}^{3}\right)\end{array}$ & 2,348 & 2,360 & 2,371 & 2,376 & 2,353 & 2,359 & 2,377 & 2,406 & 2,414 & 2,407 \\
\hline $\begin{array}{l}\text { Vazios agregado mineral, } \\
\text { VAM (\%) }\end{array}$ & 15,9 & 16,2 & 16,2 & 16,9 & 17,2 & 15,4 & 15,6 & 14,9 & 15,6 & 15,8 \\
\hline $\begin{array}{l}\text { Rel. betume/vazios, RBV } \\
(\%)\end{array}$ & 59,0 & 65,3 & 73,0 & 76,9 & 82,0 & 60,9 & 68,3 & 80,3 & 84,8 & 90,8 \\
\hline Estabilidade $(\mathrm{N})$ & 10.795 & 12.426 & 12.364 & 12.669 & 11.075 & 12.896 & 13.986 & 13.840 & 13.224 & 13.720 \\
\hline
\end{tabular}



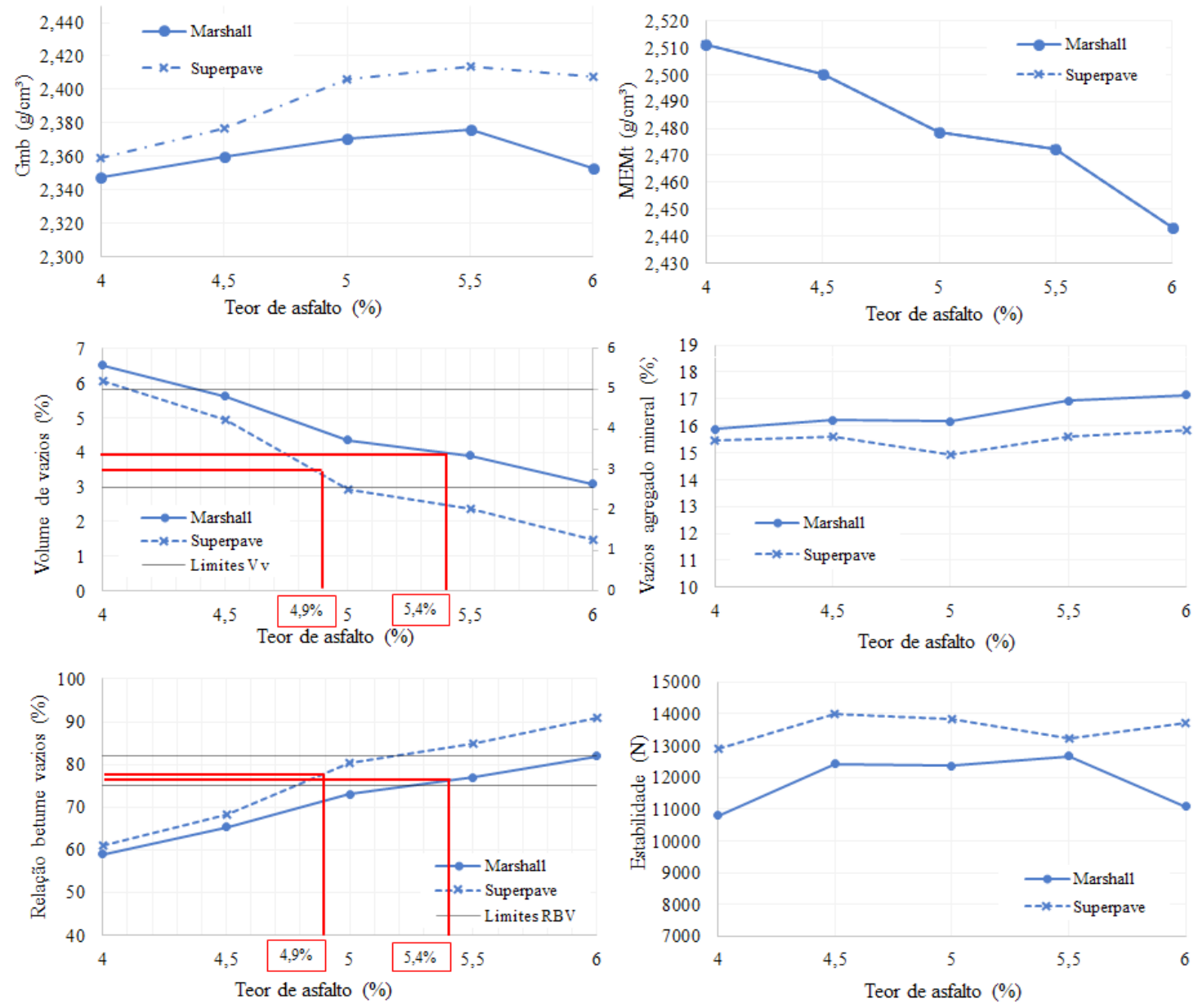

Figura 5 - Curvas em função do teor de asfalto misturas estudadas.

Analisando os resultados do volume de vazios, nos corpos de prova dosados com os teores de 4 a $6 \%$ de ligante, é possível perceber que todas as amostras compactadas pelo soquete Marshall apresentaram um aumento do volume de vazios em relação as amostras compactadas no compactador giratório. Esse aumento é progressivo e crescente, ou seja, nos teores mais elevados o aumento é mais significativo. Esse comportamento corroboraria a hipótese de que o compactador giratório consegue densificar melhor a mistura asfáltica, através da pressão aplicada em cada giro.

O teor ótimo de ligante foi selecionado a partir dos parâmetros de dosagem volume de vazios $(\mathrm{Vv})$ e relação betume/vazios (RBV), já que a alternativa tradicional de escolha pelo volume de vazios correspondente à 4\%, apresentou valores de RBV fora da especificação DNIT 031/2006 - ES. Seguindo este critério, os teores ótimos definidos foram de 5,4\% e 4,9\%, para as misturas Marshall e Superpave, respectivamente. Alguns autores [5] também relatam a redução no teor de ligante ótimo quando da utilização do compactador giratório, em comparação com o soquete Marshall. A Figura 6 apresenta o corpo de prova de cada uma das misturas estudadas. 


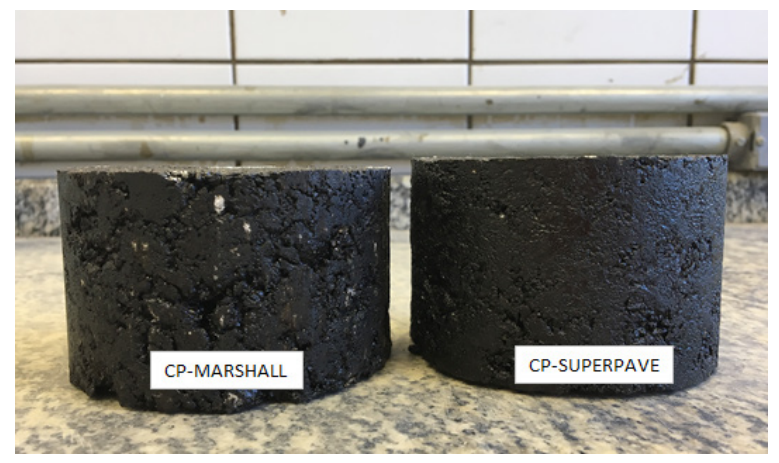

Figura 6 - Corpos de prova das misturas estudadas.

Os resultados da caracterização mecânica dos corpos de prova moldados com o teor ótimo de ligante de cada uma das misturas estáo apresentados na Tabela 4. A Figura 7 apresenta graficamente os resultados dos ensaios de resistência à tração e módulo de resiliência, respectivamente.

Tabela 4 - Caracterização mecânica das misturas (RT e MR).

\begin{tabular}{ccc}
\hline Parâmetro & Marshall & Superpave \\
\hline RT $(\mathrm{MPa})$ & 1,398 & 1,362 \\
MR $(\mathrm{MPa})$ & 3853 & 3712 \\
\hline
\end{tabular}
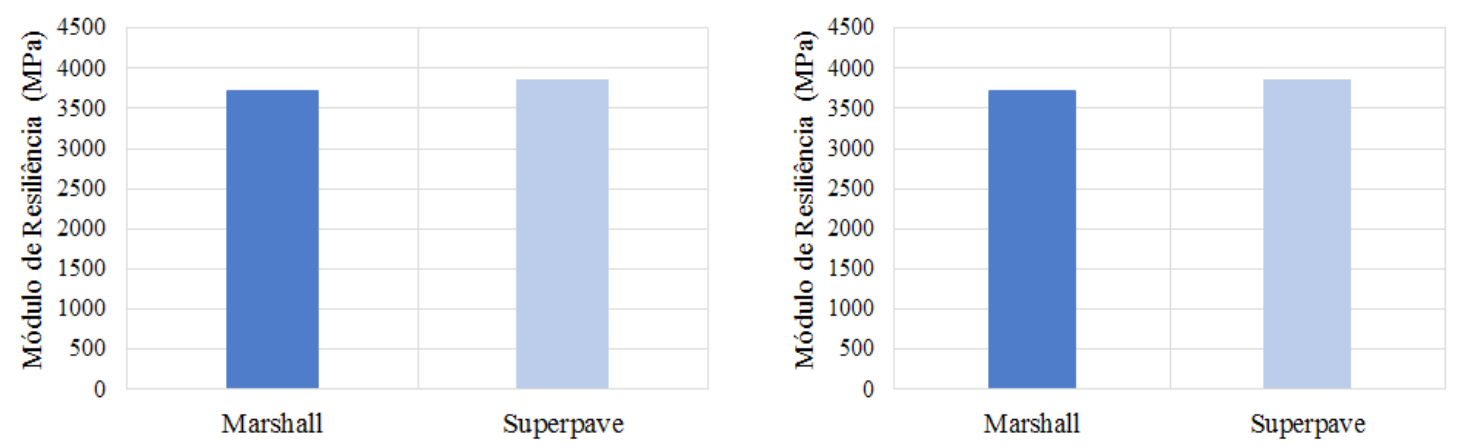

Figura 7 - Resultados resistência a tração e módulo de resiliência, respectivamente.

A norma DNIT 031/2006 especifica o valor de RT mínimo de 0,65 MPa para concretos asfálticos, sendo assim, conforme apresentado na Figura 9, as duas misturas atendem à especificação. Apesar de apresentar valores de RT diferentes, ligeiramente menor para a mistura compactada no compactador giratório Superpave, não há diferença estatística entre os valores encontrados para os dois processos de compactação, analisados através da diferença das médias com relação ao desvio padrão $(3 \rrbracket)$. Ainda, vale ressaltar que os resultados de estabilidade Marshall foram maiores para as amostras Superpave do que para as amostras Marshall.

Quanto aos resultados de módulo de resiliência também não há diferença estatística entre os valores, porém, as amostras compactadas no compactador giratório Superpave apresentaram re- 
sultados de módulo de resiliência maiores do que as amostras compactadas no soquete Marshall, possivelmente por conta do menor teor de ligante das misturas Superpave que, sendo mais rígidas neste caso, apresentam uma menor deformação frente à tensão aplicada o que implica em uma menor deformabilidade em campo. Essa diferença nos valores de MR e RT também foi encontrado em outras pesquisas dessa natureza [6], que concluem que a dosagem Marshall e Superpave para energias equivalentes podem até fornecer teores de ligante de projeto similares, porém em termos de MR e RT podem apresentar valores diferentes pois as estruturas do esqueleto mineral geradas pela compactação por impacto (Marshall) e por amassamento (Superpave) são distintas e interferem no valor dessas propriedades mecânicas.

\section{Conclusóes}

Os resultados dessa pesquisa apontam para a redução do teor de ligante das misturas asfálticas compactadas pelo compactador giratório Superpave, de $0,5 \%$ no teor de ligante, mantendo os parâmetros de resistência a tração e módulo de resiliência nos mesmos níveis encontrados para as amostras compactadas pelo soquete Marshall. Sendo assim, este melhor desempenho está relacionado unicamente à forma de compactação, a qual influencia o teor ótimo de ligante, já que tanto o tipo de materiais, composição granulométrica e temperaturas de usinagem e compactação foram mantidas constantes no planejamento do experimento.

Ainda, a partir da análise dos resultados do comportamento mecânico, no caso das amostras compactadas por amassamento, no compactador giratório Superpave, é possível inferir que as mesmas deformaram menos a um dado nível de tensão, quando comparadas as amostras compactadas pelo compactador Marshall, acarretando em misturas menos suscetíveis à deformação em campo. De qualquer forma, não foram analisados os comportamentos dessas misturas asfálticas em relação aos ensaios de fadiga e deformação permanente, sendo estes parâmetros importantes para avaliação de desempenho das misturas.

Por fim, é importante ressaltar que pesquisas que tratem da avaliação de outros métodos, além do normalizado método Marshall, onde a dosagem possa refletir de forma mais efetiva em campo, aplicados a materiais típicos brasileiros, tem importância significativa para o conhecimento sobre métodos de dosagem racionais de misturas asfálticas no Brasil.

\section{Agradecimentos}

Os autores agradecem ao Laboratório de Pavimentação Armando Martins Pereira (LAMP) e ao Programa de Pós-Graduação em Engenharia de Construção Civil (PPGECC), da Universidade Federal do Paraná (UFPR), pela disponibilização de laboratórios, equipamentos e apoio à pesquisa, e, ao BNDES e à CAPES, pelo apoio financeiro. 


\section{Referências}

[1] BERNUCCI, L.B., MOTTA, L.M.G., CERATTI, J.A.P.; SOARES, J.B. Pavimentaçáo Asfáltica - Formação Básica para Engenheiros. 1. ed. Rio de Janeiro: PETROBRAS:ABEDA, 2007.

[2] ROBERTS, F. L.; MOHAMMAD, L. N.; WANG, L. History of Hot Mix Asphalt Mixture Design. Journal of Materials in Civil Engineering, 2002. 279-293.

[3] LEANDRO, R. P. Avaliaçáo do comportamento mecânico de corpos de prova de misturas asfálticas a quente resultantes de diferentes métodos de compactaçáo. 289 p. Tese (Doutorado em Engenharia de Transportes) Departamento de Engenharia de Transportes - Universidade de São Paulo, Escola Politécnica, Sáo Paulo, 2016.

[4] ASPHALT INSTITUTE. Superpave mix design: Superpave series SP-2. E. ed. [S.I.]: [s.n.], 2001.

[5] JITSANGIAM, P.; CHINDAPRASIRT, P.; NIKRAZ, H. An evaluation of the suitability of SUPERPAVE and Marshall asphalt mix designs as they relate to Thailand's climatic conditions. Construction and Building Materials, 2013, v.40, 961-970.

[6] NASCIMENTO, L.; LEITE, L.; CAMPOS, E. F.; MARQUES, G.; MOTTA, L. Uso da tomografia computadorizada e de imagens digitais para o estudo de misturas asfálticas. In: ENCONTRO DO ASFALTO, 18, 2006, Rio de Janeiro, Anais... Rio de Janeiro: IBP, 2006.

[7] ASPHALT INSTITUTE. The Bailey Method: Achieving Volumetrics and HMA Compactability. Lexington, 2014. Disponível em: <http://www.asphaltinstitute.org/ bailey-method-achieving-volumetrics-and-hma-compactibility/>. Acesso em: 05 jul. 2016.

[8] CUNHA, M. B. C. Avaliaçáo do método Bailey de seleção granulométrica de agregados para misturas asfálticas. 118 p. Dissertação (Mestrado em Engenharia Civil) - Setor de Transportes, - Universidade de São Paulo, Escola de Engenharia de São Carlos, São Carlos, 2004. 